University of Nebraska - Lincoln

DigitalCommons@University of Nebraska - Lincoln

West Central Research and Extension Center, North Platte

Agricultural Research Division of IANR

2-2012

\title{
True integrated weed management
}

Stephen L. Young

University of Nebraska - Lincoln, steve.young@usu.edu

Follow this and additional works at: https://digitalcommons.unl.edu/westcentresext

Part of the Agriculture Commons

Young, Stephen L., "True integrated weed management" (2012). West Central Research and Extension Center, North Platte. 23.

https://digitalcommons.unl.edu/westcentresext/23

This Article is brought to you for free and open access by the Agricultural Research Division of IANR at DigitalCommons@University of Nebraska - Lincoln. It has been accepted for inclusion in West Central Research and Extension Center, North Platte by an authorized administrator of DigitalCommons@University of Nebraska - Lincoln. 
Published in Weed Research 52:2 (April 2012), pp. 107-111; doi: 10.1111/j.1365-3180.2012.00903.x

Copyright (C) 2012 Stephen L. Young. Published by European Weed Research Society and John Wiley \& Sons, Inc.

Used by permission.

Published online February 16, 2012.

\title{
True integrated weed management
}

\author{
Stephen L. Young \\ University of Nebraska-Lincoln \\ West Central Research \& Extension Center, North Platte, NE 69101 \\ steve.young@unl.edu
}

\begin{abstract}
Using the simplest of definitions, integrated weed management has been described as "putting components [of weed control] together, not taking them apart." Yet, weed science has stopped at the "field edge" in assembling the components into a truly integrated approach. What is keeping weed scientists from developing real integrated weed control regardless of space and time? The answer to this question lies with our colleagues in the engineering and computer science fields, who have made significant advances in developing automated machinery for real-time detection and control of weeds in cropping systems. By using the latest technologies that can quickly identify weeds and react with precisely targeted applications, conceptually, weed control tools could be integrated for use at anytime and at any point in a field. This paper provides justification for using a single platform in the field that can instantaneously assess individual weeds and determine the most appropriate control method, simultaneously. In addition, I have modified an existing concept design to show the potential for a highly responsive weed management system that can transcend spatiotemporal restrictions and within-field variability.
\end{abstract}

Keywords: automation, machine vision, micro-rates, sensors, site-specific management, targeted applications, weed biology

\section{Introduction}

Crop production is most often by the hectare, and in most cases, inputs are applied in kilograms and liters and averaged for an entire field using equipment that spans multiple crop rows (Tilman et al., 2002). While studies have shown within-field variability to be large at both macro- and micro-scales (Earl et al., 2003; Steiner et al., 2008; Verhulst et al., 2009), the overall adoption of technology for variable rate and site-specific management has lagged behind its development (Bullock \& Lowenberg-DeBoer, 2007; HakJin et al., 2009).

In cropping systems, the needs of individual plants, including weeds, can change dramatically over very short distances. There are obvious requirements of plants, such as nutrients and water, and more subtle requirements, such as light, air and microbial interactions. In most conditions, plants must compete for resources, which end up diminishing their overall growth and development. Weeds in production systems often occur in patches of various sizes or as individuals growing among crop plants, yet they are managed in a way that is similar to the crop, large-scale and uniform. A combination of control methods, such as chemical, mechanical and cultural, are used at different times of the season or over several seasons, but rarely are single weed plants targeted. In many areas, farmers indicate that weeds are the number one problem (Gibson et al., 2005), yet weeds, like crop plants, are not managed at the individual plant scale, although this is becoming a focus of some research (van Evert et al., 2011; Zijlstra et al., 2011). 


\section{Current Integrated Weed Management (IWM)}

Integrated weed management has been defined as an approach to managing weeds, which relies on multiple tactics to stress weed populations and increase the competitive ability of the crop (Smith et al., 2010). According to Swanton et al. (2008), integrated weed management is a cropping systems approach that relies on essential knowledge for its implementation and focuses on crop health. They view it as a series of interactions among several weed control components. Thomas et al. (2010) state that at the core of integrated weed management lies the principle of using knowledge of organisms and that of the agroecosystem and a variety of tools, to provide the needed selection pressure to keep the competitive balance in favor of the crop to the detriment of undesired species (e.g. weeds).

Much information exists on agronomic weeds, including their history, biology, ecology and methods for control. The integration of this information should result in knowledge-based evaluations and decisions that will guide their management (Swanton et al., 2008). In its present form, integrated weed management focuses on the reduction in weeds using individual techniques over a single season or multiple seasons and typically incorporates the use of broadcast-type equipment (e.g. cultivators, sprayers, mowers). As production costs have risen, weed control research has been conducted on ways to lower either inputs or the number of operations. In the case of herbicides, most studies have focused on reducing inputs through low-volume, overthe-row, or variable rate applications (Bohannan \& Jordan, 1995; Riar et al., 2011). These techniques have resulted in fewer chemicals being released, but they have done little to improve application efficacy, where treatments are made directly to the target (but see van Evert et al., 2011; Nieuwenhuizen et al., 2010; Sogaard \& Lund, 2007).

While integrated weed management has become commonplace in the weed science research community (Hamill et al., 2004), few studies are conducted in a broader context that incorporates site-specific treatments using real-time decision support systems across wide-ranging spatiotemporal conditions. Basic and applied weed science research has not often focused on the use of advanced technology, which may be due to the development of highly effective chemical controls (Gianessi \& Reigner, 2007). As technology advances, so too should the traditional approaches related to weed management, especially for addressing field variability and the economics of crop production systems. As stated by Davis et al. (2009), 'it is long past time for weed scientists to move beyond a dominating focus on herbicide efficacy testing and address the basic science underlying complex issues in vegetation management at many levels of biological organization currently being solved by others [biological systems engineers, computer scientists]'. Similar sentiments are echoed by ENDURE (European Network for Durable Exploitation of Crop Protection Strategies), a European Network of Excellence (http://www.endure-network.eu), which sees integrated pest management as a continuously improving process with locally adapted solutions that contribute to diversifying agricultural systems.

\section{The need for change}

For agronomic weeds, herbicides, a heavily relied upon management tool, are receiving increased negative attention, because of the environmental issues of off-target movement and trace residues now found on fruits and vegetables (Tadeo et al., 2000; Barbash et al., 2001). Other disturbances, such as cultivation or plowing, can result in excessive soil loss that lowers productivity and contributes to undesirable environmental conditions, such as siltation of waterways, flash flooding and disruption of stream ecology (Pimentel et al., 1995). The environmental and economical impacts from the use of broadcast-type weed control tools are a major concern for producers, researchers and the public and should be enough incentive to focus more research on the use of advanced technology to develop truly integrated weed management programs.

Sensors and guidance technology are being developed for cropping systems that would allow for realtime recognition of target plants (e.g. weeds) and potential improvements in the discrete and targeted application of management tools at very fine spatiotemporal scales (Singh et al., 2011). By bringing a greater number of integrated weed management tools to the field for targeted and precise applications, the heterogeneous nature of agroecosystems, particularly weeds, can be managed in a safer and more sustainable way.

Because of rising public interest in sustainability and protection of natural resources and readily available research-grade technology, a greater number of studies are needed to identify approaches and develop systems that are truly integrated across spatiotemporal scales. By combining the knowledge-base on weeds (e.g. weed growth and development) with the developments in engineering and computer science, increases can be realized for environmental protection, public safety and grower profits.

\section{New engineering developments}

The development of machine-guided technologies for precision weed control has advanced rapidly in re- 
cent decades (Slaughter et al., 2008; Singh et al., 2011). The robotics of weed management includes sensors for measuring biological and physical properties, decisionmaking capabilities to determine necessary agroecosystem manipulation(s) and actuators for making treatments (Harrell et al., 1988). Sensor-based equipment is being tested for accurate identification of pests (e.g. weeds) in the field at the individual organism scale in real-time (Tellaeche et al., 2008, 2011; Singh et al., 2011). Numerous research programs in the field of biological systems engineering in the US, Europe and around the world are making powerful discoveries in robotics and vision systems for use in agricultural production systems (Grift et al., 2008), including optically guided inter-row weed cultivators (Tillett and Hague Technology, Ltd., UK), autonomous tractors available in 2012 (Kinze Manufacturing, Inc., USA) and automated pruning and harvesting machine prototypes (Vision Robotics Corporation, USA).

Technological advancements specific to weed control have been made in many areas, including mechanical, chemical, thermal and electrical (Slaughter et al., 2008). For example, in the United Kingdom, a weeding robot and integrated band steaming were shown by Sørensen et al. (2005) to potentially reduce labor demand by up to $85 \%$ in sugar beet and $60 \%$ in carrots. In addition to sugar beet, mechanical weed removal using an actuator and hoe has been demonstrated for cotton, tomato, lettuce, broccoli and melon (Garrett, 1966; Astrand \& Baerveldt, 2002).

The first published report of selective spot herbicide application technology was by Lee et al. (1999), who developed a prototype system with micro-controller actuated-specific solenoid valves, delivering liquid to the spray ports, based on the machine vision generated weed map and robot odometry. Improvements to this first prototype have been made by Lamm et al. (2002) and others. Published research has begun to increase on the assessment of micro-dose herbicide applications that target the weed in cropping systems (Giles et al., 2004; Sogaard \& Lund, 2007; Nieuwenhuizen et al., 2010). In glasshouse studies, a typical rate of glyphosate $\left(1.5 \mathrm{~kg} \mathrm{ha}^{-1}\right)$ reduced by over $75 \%$ applied at $10 \mu \mathrm{L}$ directly to the cotyledon leaves of Abutilon theophrasti Medic. (velvetleaf) killed $100 \%$ of the plants (Young, personal observations).

Several other weed control tools have been investigated for use in combination with robotic systems, including flame weeding, hot water, organic oils and high voltage electrical discharge (Slaughter et al., 2008). With advances in sensors and guidance technology, integrated weed management could change dramatically. By using technologically equipped machinery that can target individual weeds in real-time, there is no limit to the number of control tools for use in the field at any one time. The advances in the biological systems engineering field are evidence that 'given enough time, an engineer can build anything.' Biological research and the latest technological developments in weed control have the potential to radically change the current research approach to integrated weed management and help significantly reduce environmental impacts (e.g. drift, off-target movement) and the high cost of inputs and labor.

\section{True integrated weed management in the field}

Sensors and guidance systems are currently being developed for real-time identification of weedy plants, and research on targeted control systems is not far behind (Christensen et al., 2009; Kempenaar et al., 2011). Being able to combine recognition and application technology into a single platform is a critical area of research that requires biology, engineering and computer programming. There is a need for the development of a single platform with sensors and decision support software that has multiple application technologies for directed weed management. Ideally, a self-guided machine is needed that could comb the field in a systematic way to identify weeds and then apply the necessary control tool (e.g. spray, mow, cultivate) at the individual plant or patch scale (Figure 1).

From a biological approach, successfully integrating weed management requires an understanding of three key components: the effect of treatments on weed populations, weed growth and development stages and the critical period for applying control tools (Swanton et al., 2008). Control tools (e.g. mowing, spraying, cultivating) have differing effects on weeds, and without a complete understanding of the life history of the target weed(s) and crop, the development of effective and efficient robotic systems will be extremely challenging,

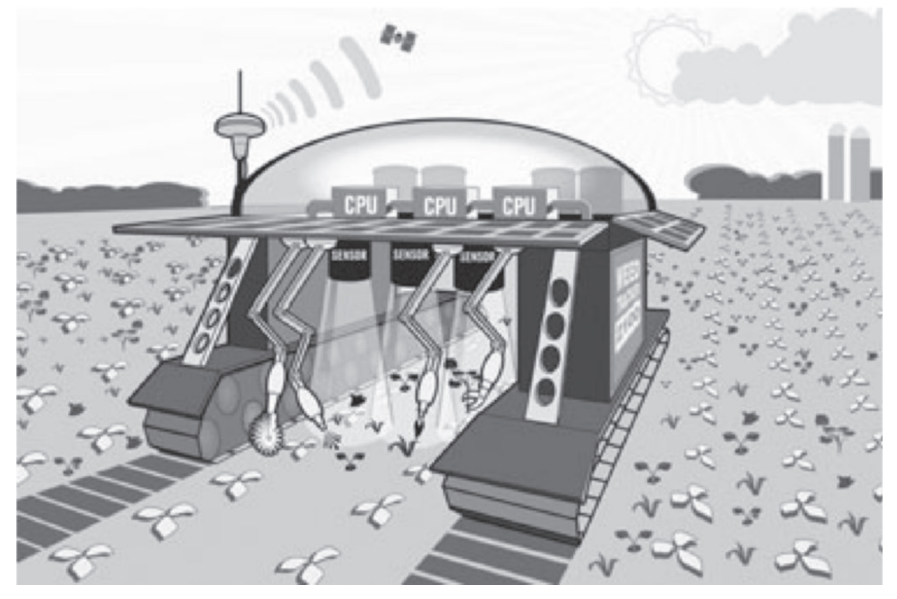

Figure 1. Robotic weed control in the future using multiple tools with simultaneous application as depicted by S. L. Young. 
if not impossible. In all crops, there exists a period in which weed control is critical to avoid incurring yield loss (Knezevic et al., 2002). An autonomous robotic system that is designed without consideration for timing of weed removal will perform poorly in current cropping systems. Such a robotic system that can respond to critical periods of crop growth must be either manually sent into the field or programmed to perform weed control operations that are in synchrony with crop growth stage.

In integrated weed management, the identification of weeds and applications for their control could occur at various spatiotemporal scales using the latest machinebased guidance systems with sensors and decision support systems. A single-platform system with many different weed control tools will bring greater flexibility and responsiveness in managing current cropping systems (Figure 1). Individual weeds can be killed with a tool (e.g. spraying, cultivating, cutting) that is selected by an onboard computer with pre-programmed information on weed characteristics and images and tool efficacy. As the platform moves through a field, weeds are identified, categorized and killed without damaging the crop. For each field, a map is generated that has the location of the weed and the control tool used. The map is stored on the computer to prevent repeated use of the same tool for the next operation. The environmental conditions, such as soil moisture, wind speed, precipitation, temperature and relative humidity, are measured using instrumentation located onboard the single-platform system. Ultimately, this real-time integrated weed control system will reduce reliance on one tool (e.g. spraying, cultivating) and eliminate the current problems of herbicide resistant weeds, off-target movement and soil erosion, while lowering overall input costs. The primary constraint of this system would be that weed control will decline dramatically with weed maturation, a fact that has been known since the dawn of agriculture and is still being addressed today.

It is anticipated that with greater collaboration between the fields of weed science and biological and computer science, the following two goals can be achieved: (i) combination of weed management tools into one operation to allow for a truly integrated system and (ii) advance of sustainable integrated weed management programs through reductions in environmental contamination and human exposure to chemicals, with fewer inputs needed to economically control weeds.

\section{Final thoughts}

Combining recognition and application technology into a single platform for fast and efficient weed control across spatiotemporal scales will require precise in- formation on weed biology and ecology and continued testing of technology for a wide range of field conditions (Slaughter et al., 2008; Singh et al., 2011). While a single platform for conducting real-time integrated weed management is futuristic, it is now possible to begin assembling the components and to think broadly while working across disciplines. One of the many common goals for biologists and engineers working in agriculture is the elimination of weeds while minimizing negative impacts to the environment and economics. It is apparent that technology can assist in addressing the current limitations of integrated weed management at micro-scales and at the same time help to meet the demand for food, feed and fiber in a sustainable way at macro-scales.

\section{References}

Astrand B \& Baerveldt AJ (2002) An agricultural mobile robot with vision-based perception for mechanical weed control. Autonomous Robots 13, 21-35.

Barbash JE, Thelin GP, Kolpin DW, et al. (2001) Major herbicides in ground water: Results from the national waterquality assessment. Journal of Environmental Quality 30, 831-845.

Bohannan DR \& Jordan TN (1995) Effects of ultra-low volume application on herbicide efficacy using oil diluents as carriers. Weed Technology 9, 682-688.

Bullock DS \& Lowenberg-DeBoer J (2007) Using spatial analysis to study the values of variable rate technology and information. Journal of Agricultural Economics 58, 517-535.

Christensen S, Sogaard HT, Kudsk L et al. (2009) Site-specific weed control technologies. Weed Research 49, 233-241.

Davis AS, Hall JC, Jasieniuk M, et al. (2009) Weed science research and funding: A call to action. Weed Science 57, 442-448.

Earl R, Taylor JC, Wood GA, et al. (2003) Soil factors and their influence on within-field crop variability, part 1: Field observation of soil variation. Biosystems Engineering 84, 425-440.

van Evert FK, Samsom J, Polder G, et al. (2011) A robot to detect and control broad-leaved dock (Rumex obtusifolius L.) in grassland. Journal of Field Robotics 28, 264-277.

Garrett RE (1966) Device designed for synchronous thinning of plants. Agricultural Engineering 47, 652-653.

Gianessi LP \& Reigner NP (2007) The value of herbicides in U.S. crop production. Weed Technology 21, 559-566.

Gibson KD, Johnson WG, \& Hillger DE (2005) Farmer perceptions of problematic corn and soybean weeds in Indiana. Weed Technology 19, 1065-1070.

Giles DK, Downey D, Slaughter DC, et al. (2004) Herbicide micro-dosing for weed control in field grown processing tomatoes. Applied Engineering in Agriculture 20, 735-743.

Grift T, Zhang Q, Kondo N, et al. (2008) A review of automation and robotics for the bioindustry. Journal of Biomechatronics Engineering 1, 37-54.

HakJin K, Sudduth KA \& Hummel JW (2009) Soil macronutrient sensing for precision agriculture. Journal of Environmental Monitoring 11, 1810-1824. 
Hamill AS, Holt JS, \& Mallory-Smith CA (2004) Contributions of weed science to weed control and management. Weed Technology 18, 1563-1565.

Harrell RC, Slaughter DC, \& Adsit PD (1988) Robotics in agriculture, in: International Encyclopedia of Robotics Applications and Automation (ed. RC Dorf), 1378-1387. John Wiley \& Sons, Inc., New York, USA.

Kempenaar C, Lotz LP, Snel JH, et al. (2011) Predicting herbicidal plant mortality with mobile photosynthesis meters. Weed Research 51, 12-22.

Knezevic SZ, Evans SP, Blankenship EE, et al. (2002) Critical period for weed control: The concept and data analysis. Weed Science 50, 773-786.

Lamm RD, Slaughter DC, \& Giles DK (2002) Precision weed control system for cotton. Transactions of the American Society of Agricultural Engineers 45, 231-238.

Lee WS, Slaughter DC, \& Giles DK (1999) Robotic weed control system for tomatoes. Precision Agriculture 1, 95-113.

Nieuwenhuizen AT, Hofstee JW, \& van Henten JW (2010) Performance evaluation of an automated detection and control system for volunteer potatoes in sugar beet fields. Biosystems Engineering 107, 46-53.

Pimentel D, Harvey C, Resosudarmo P, et al. (1995) Environmental and economic costs of soil erosion and conservation benefits. Science 267, 1117-1123.

Riar DS, Ball DA, Yenish JP, et al. (2011) Light-activated, sensor-controlled sprayer provides effective post-emergence control of broadleaf weeds in fallow. Weed Technology 25, 447-453.

Singh K, Agrawal KN, \& Bora GC (2011) Advanced techniques for weed and crop identification for site specific weed management. Biosystems Engineering 109, 52-64.

Slaughter DC, Giles DK, \& Downey D (2008) Autonomous robotic weed control systems: A review. Computers and Electronics in Agriculture 61, 63-78.

Smith RG, Mortensen DA \& Ryan MR (2010) A new hypothesis for the functional role of diversity in mediating resource pools and weed-crop competition in agroecosystems. Weed Research 50, 37-48.
Sogaard HT \& Lund I (2007) Application accuracy of a machine vision-controlled robotic micro-dosing system. Biosystems Engineering 96, 315-322.

Sørensen CG, Madsen NA, \& Jacobsen BH (2005) Organic farming scenarios: operational analysis and costs of implementing innovative technologies. Biosystems Engineering 91, 127-137.

Steiner U, Burling K, \& Oerke EC (2008) Sensor use in plant protection. Healthy Plants 60, 131-141.

Swanton CJ, Mahoney KJ, Chandler K, et al. (2008) Integrated weed management: Knowledge-based weed management systems. Weed Science 56, 168-172.

Tadeo JL, Sanchez-Brunete C, Perez RA, et al. (2000) Analysis of herbicide residues in cereals, fruits and vegetables. Journal of Chromatography A 882, 175-191.

Tellaeche A, Burgos-Artizzu XP, Pajares G, et al. (2008) A new vision-based approach to differential spraying in precision agriculture. Computers and Electronics in Agriculture 60, 144-155.

Tellaeche A, Pajares G, Burgos-Artizzu XP, et al. (2011) A computer vision approach for weeds identification through support vector machines. Applied Soft Computing 11, 908-915.

Thomas AG, Légère A, Leeson JY, et al. (2010) Weed community response to contrasting integrated weed management systems for cool dryland annual crops. Weed Research 51 , 41-50.

Tilman D, Cassman KG, Matson PA, et al. (2002) Agricultural sustainability and intensive production practices. Nature 418, 671-677.

Verhulst N, Govaerts B, Sayre KD, et al. (2009) Using NDVI and soil quality analysis to assess influence of agronomic management on within-plot spatial variability and factors limiting production. Plant and Soil 317, 41-59.

Zijlstra C, Lund I, Justesen AF, et al. (2011) Combining novel monitoring tools and precision application technologies for integrated high-tech crop protection in the future. Pest Management Science 67, 616-625. 